Raaijmakers, M.F., Dekker, J., Dejonckere, P.H., Zee, J. van der. Medical and educational fields in logopedics in the Netherlands: a comparison in historical and European perspective. Folia

\begin{tabular}{|l|l|}
\hline $\begin{array}{l}\text { Postprint } \\
\text { Version }\end{array}$ & 1.0 \\
\hline $\begin{array}{l}\text { Journal website } \\
\text { Pubmed link }\end{array}$ & $\underline{\text { http://content.karger.com/produktedb/produkte.asp?typ=fulltext\&file=fpl50080 }}$ \\
\hline DOI & $\underline{10.1159 / 000021453}$ \\
\hline
\end{tabular}

This is a NIVEL certified Post Print, more info at http://www.nivel.eu

\title{
Medical and Educational Fields in Logopedics in The Netherlands: A Comparison in Historical and European Perspective
}

\author{
M.F. RAAIJMAKERS ${ }^{\mathrm{A}}$ J. DEKKER $^{\mathrm{A}}$ P.H. DEJONCKERE ${ }^{\mathrm{B}}$ J. VAN DER ZEE $^{\mathrm{A}}$ \\ ${ }^{a}$ Netherlands Institute of Primary Health Care and ${ }^{b}$ Institute of Phoniatrics, Utrecht, The \\ Netherlands \\ J. Dekker Netherlands Institute of Primary Care PO Box 1568 NL-3500 BN Utrecht (The \\ Netherlands) Tel. +31 302729700, Fax +31 302729729
}

\begin{abstract}
This study describes differences between medical and educational fields in logopedics practice in The Netherlands. This dichotomy of fields is also found in other Western European countries and may result from the historical development of the profession. The four settings where logopedists work the most (institutional care, private practice, community care and special schools) were studied. One hundred and seventy-two logopedists in 103 practices or departments collected data on 1,761 patients. For each patient a standard registration form was filled in, containing information on (i) patient characteristics, (ii) logopedic diagnostic assessment, and (iii) aspects of treatment. The historical dichotomy into medical and educational fields is still demonstrable in present-day logopedics in The Netherlands. However, the settings within each field also show some differences. Private practice shows a mixture of medical and educational characteristics.
\end{abstract}

\section{INTRODUCTION}

Logopedists may practice their profession in a variety of fields which may be grossly dichotomised into fields of medical care and education [1, 2]. This dichotomy distinguishes the profession from other paramedical professions like occupational therapy, which are practiced mainly in medical care [3]. The duality of logopedic fields is also shown in other countries, as it may be a result of the historical development of the profession as a whole. The question arises to what extent differences exist between medical and educational fields in current logopedics practice in the Netherlands. To clarify this question, the next paragraphs outline a brief history of the profession and a short description of the present situation in other Western European countries.

\section{Historical Background of the Profession}

The education of the deaf was the first branch of applied logopedics that developed in the 16th century [4]. This was done by teachers in Spain, followed by teachers in France, Germany and Scotland [5]. In the 18th century teachers started to treat stutterers as well, while teachers of eloquence and singing also treated voice problems [5]. At the end of the 19th century, teachers established clinics for the pedagogical correction of speech defects in Austria, Germany and Denmark [6]. Novel developments in medical science in the second half of the 19th century created new possibilities for diagnosis and treatment of voice, speech and language disorders. For example, the invention of the laryngeal mirror, the discovery of 
Raaijmakers, M.F., Dekker, J., Dejonckere, P.H., Zee, J. van der. Medical and educational fields in logopedics in the Netherlands: a comparison in historical and European perspective. Folia Phoniatrica et Logopaedica: 1998, 50(2), 80-91

the localisation of aphasia and developments in physiology, neurology, otology and audiology [7]. Around 1900, the new medical science of phoniatrics was founded. From two clinics, in Vienna and Berlin, medically oriented phoniatrics was then brought to prosperity. In both cities, co-operating teachers and physicians gave courses in speech disorders and treatment [6, 7]. In the 1920s special speech schools as well as speech clinics in hospitals were founded in most countries in Europe. Meanwhile an independent development of the profession took place in the United States. Here scientific disciplines such as psychology, pedagogics and linguistics joined forces in 'speech pathology', a behavioural science in which the medical disciplines were exceptions [7, 8]. After the First World War the value of logopedics as a separate profession became apparent. Co-operation of logopedists with physicians was established as the need to provide rehabilitation services became clear [5]. At this time the terms 'logopedics' and 'phoniatrics' were distinguished. In the study and treatment of disorders of voice, speech and language, 'logopedics' was interpreted as the pedagogical part (which has much ground in common with medical science) and 'phoniatrics' as the medical part [9]. In 1924, physicians and logopedists joined forces in the foundation of the International Association of Logopedics and Phoniatrics. Finally, in the 1930s logopedics became an independent profession. A steady increase in the number of logopedists and work places was shown in the years to come [5].

\section{Present Situation of Logopedics in Western Europe}

As was described before, logopedics as a profession originated from disciplines of education and medicine, and was influenced later on by other disciplines like psychology, linguistics etc. Nowadays, logopedics in different countries still varies in the extent to which medical and/or educational aspects are accentuated in professional practice. Related to this also differences in the legal position of logopedics, work settings and relations with referrers may be observed.

The profession of logopedics is defined as a health care profession in all countries in the European Community, except Denmark [10]. In Denmark the profession is primarily related to education and logopedists are public employees. They are formally employed as teachers in primary schools and in county speech institutes $[11,12]$. In Norway, too, logopedics is considered part of special education [12]. In Switzerland and Spain logopedics is related to both education and health care [10, 12; S. Ugolini, personal commun.]. In some countries the situation is complicated as a number of closely related professions may exist next to logopedics, for example in Germany [12-14]. Logopedists in all Western European countries may work in hospitals and other intramural institutions as well as in special education and private practice [10, 12, 14; S. Ugolini, personal commun.]. Logopedists work in ordinary primary education in all countries, except France, Germany, and Italy [10, 12, 14; S. Ugolini, personal commun.].

In most countries a medical referral is required. Thus, the relation of logopedists with the medical professions is now more or less regulated by law. In Denmark, Sweden, Great Britain and Ireland medical referral may be the rule, but not formal referral is obligatory. In these countries patients may refer themselves or they may be referred by health visitors, educational services, school nurses or social services [14, 15; P. Kitzing, personal commun.; B. Kjær, personal commun.].

\section{Present Situation in The Netherlands}

In The Netherlands logopedics is regulated by law as an allied health profession. The fields where logopedists work the most are private practice, intramural institutions, community care (for children in primary schools) and special schools (for example for children with behavioural and/or learning disorders) [16]. Logopedists working in private practices must have an agreement with a health care insurer for reimbursement. Insurance companies usually demand a referral by a physician. Logopedists in institutional care are usually employed by the institution. In community care, emphasis is on prevention and early intervention of communication disorders in primary school children. These logopedists may 
Raaijmakers, M.F., Dekker, J., Dejonckere, P.H., Zee, J. van der. Medical and educational fields in logopedics in the Netherlands: a comparison in historical and European perspective. Folia Phoniatrica et Logopaedica: 1998, 50(2), 80-91

be employed by the local government or by school advisory services. In contrast, logopedists working in special schools are employed by the school board and paid by the ministry of education.

The training of logopedists is offered in special non-university 'colleges of higher education', so the programme is not linked to any medical or pedagogical faculty as may be the case in other countries. The 4-year programme leads to a diploma qualification [20].

\section{Present Study}

The practice of the profession in different countries varies because of political, administrative and financial influences [17]. But the variety in logopedics could also be explained by the extent to which emphasis is on the 'education' or on the 'medical care' branch of the profession. For example, in some countries most attention seems to be given to children with speech and language disorders, whereas in other countries the work of logopedists focusses on hospital-based patients [20]. Furthermore, it seems that within the countries logopedists may work in a variety of settings, of which some seem to be related to medical care (e.g. hospitals) and other may have developed from the educational origin of the profession (e.g. schools). Therefore, in order to get insight into the profession of logopedics as it is today, the historical dichotomy of the profession should be kept in mind.

The aim of this study was to describe four fields of logopedics practice in The Netherlands. Two fields were considered to have a medical background, and two fields were considered to be related to education. It was expected that characteristics of the fields comprising the main field of medical care could be distinguished from characteristics of the fields comprising education. Therefore the four fields were described and compared with regard to patient characteristics, referrers and persons who first noticed the patient, diagnostic assessments and aspects of treatment.

\section{METHOD}

\section{Design}

In the period September 1993 to September 1994, a total of 172 randomly chosen logopedists from 103 practices or departments took part in this study. They collected data on 1,761 patients applying for logopedics by means of a registration form. The first 6 months were intended for inclusion of new patients in the study. The registration form had to be completed after a maximum of 6 months, so the second half of the year was used as an extension period for treatments in progress. Four fields were included in the study, covering 88.9\% of all hours worked by all logopedists in The Netherlands [18]. Two fields were considered to be 'medical' in origin: (1) institutional care (hospitals, nursing homes, rehabilitation centres), and (2) private practices. The other two fields were regarded to be 'educational' in origin: (3) community care (for children in primary schools), and (4) special schools (e.g. for children with learning/behavioural disorders). To provide coherent groups, other fields, like audiological centres and day centres for the elderly, were excluded from participation in the survey study.

\section{Registration Form}

In a standard registration form, three information sections were distinguished. The first section concerned patient characteristics, like gender, date of birth, type of insurance and indication for referral or medical diagnosis. In the second section, diagnostic assessments made by the logopedist could be indicated. The last section included information on aspects of treatment and intervention. The first and second sections were completed after the assessment had been made. The third section in the form was completed at the end of treatment or after the registration period of 6 months. The logopedic diagnostic assessments that were used in the form were based on the International Classification of Impairments, Disabilities and Handicaps [19]. In an earlier study, the reliability of this list of diagnostic assessments showed satisfactory to good inter-rater agreement [20]. 
Raaijmakers, M.F., Dekker, J., Dejonckere, P.H., Zee, J. van der. Medical and educational fields in logopedics in the Netherlands: a comparison in historical and European perspective. Folia Phoniatrica et Logopaedica: 1998, 50(2), 80-91

\section{Procedure}

Logopedists were instructed to include in this study all new patients applying for logopedics. The aim of the study was to include 1,800 patients in total. The number of patients that would be registered by each logopedist was agreed prior to the start of the study. In each field the number of patients was planned to be in proportion with the relative size of that field, according to the study mentioned before [18].

\section{Analysis}

The four fields were compared on the following aspects: general patient characteristics, indications for referral and/or medical diagnosis, diagnostic assessments and intervention elements. The differences among the fields were tested with chi-square analysis. This analysis was only used if a maximum of $10 \%$ of the cells had an expected frequency of less than five [21]. In all cases a significance level of 0.05 was used. In some comparisons one or two fields were excluded from analysis. This was done if a certain aspect could not be interpreted for that field. For example, in educational fields the aspect 'insurance' was not analysed, because this information was not usually available.

\section{RESULTS}

\section{General}

The 1,761 patients included in this study were distributed among the four fields as had been planned prior to the start of the study. In private practice 540 patients (30\%) were included, in institutional care 342 patients (19\%), in community care 360 patients (20\%) and in the field of special schools 558 patients (31\%) were included. Herewith, the percentages were distributed among the fields in proportion to the relative size of the fields.

\section{Patient Characteristics}

Age and Gender. The age of the patients in this study is shown in table 1. In both educational fields only children were registered. In community care these mainly concerned young children up to 5 years of age, while in special schools the largest group consisted of children from 6 to 12 years. In private practices, patients of all age groups were found, although the majority of patients (63.2\%) were children up to 12 years. In institutional care most patients were older than 51 years of age. Table 1 also shows the gender of patients in the four fields. Significant differences were found. In total, $57.8 \%$ of the patients were male, whereas in institutional care $54.5 \%$ were female. This means that logopedists in institutional care see more and older women than do logopedists in other fields.

\section{[TABLE 1]}

Referring Physician and Person Who First Noticed the Patient. Physicians rarely refer children to logopedists in schools. Therefore, in table 2 the referring physicians are only presented for private practice and institutional care. Differences between these two fields were significant. Most patients in private practices were referred by general practitioners, whereas most patients in institutional care were referred by medical specialists. These specialists included ear-nose-throat specialists, nursing home specialists, rehabilitation physicians and neurologists. Table 2 also shows which person was the first to notice that a certain patient needed logopedic treatment. Differences among the four fields were all significant. Patients themselves or their guardians were most likely to notice a need for logopedics in private practices. Most patients who were first noticed by medical specialists were in institutional care, and most patients noticed by a logopedist were found in the educational fields. 
Raaijmakers, M.F., Dekker, J., Dejonckere, P.H., Zee, J. van der. Medical and educational fields in logopedics in the Netherlands: a comparison in historical and European perspective. Folia Phoniatrica et Logopaedica: 1998, 50(2), 80-91

\section{[TABLE 2]}

\section{Diagnostic Assessments}

Table 3 shows the impairments, disabilities and handicaps that were indicated as diagnostic assessments. All categories, except sensorimotor impairments and hyper/hyponasality showed significant differences among the four fields.

Some interesting differences were shown among the four fields at the level of impairments. The diagnostic assessment categories aphasia, dysarthria and impairments of swallowing were almost exclusively registered in institutional care. The category phonetic/ phonological articulation impairments was hardly ever indicated in institutional care, but particularly in both educational fields. Deviant mouth behaviour was most often indicated in community care and to a lesser degree in special schools and private practices. Impairments of auditory function, language development impairments, impairments of reading and writing as well as cognitive and psychological impairments were typical assessments in special schools. Respiratory impairments were mainly assessed in private practice and institutional care. And impairments of voice production/phonation were mostly diagnosed in private practice, although the difference with other fields was less pronounced.

At the level of disabilities, the three disabilities in communication were most often found in special schools, followed by institutional care. The disability in eating/drinking was mainly assessed in institutional care. At the level of handicaps a reverse situation was shown. Here all three handicaps were mostly registered in institutional care, followed by the field of special schools.

\section{[TABLE 3]}

\section{Aspects of Treatment}

Not for all patients applying for logopedics the diagnostic assessment or screening is followed by actual logopedic treatment. Significant differences were shown between the fields. In private practice almost all patients (98.9\%) received treatment following diagnostic assessment, in institutional care this was $89.4 \%$. In contrast, in community care only $56.1 \%$ of the patients received treatment after screening. In total $88.9 \%$ of the patients received logopedic treatment. This implies that the results on treatment aspects in the next paragraphs concern 1,567 patients in total.

Treatment Period. It was analysed for how many patients the treatment was ended within 6 months. The end of the treatment did not necessarily mean that all treatment goals were reached. It was also possible that treatment was stopped, for example because the patient was dismissed from hospital, or because the patient moved house. Because of the preventive task of logopedists in community care, treatment in this field is hardly comparable with the other fields. Therefore community care was not included in the analysis. Significant differences were found in the remaining fields. In institutional care and in private practices, most treatments are ended within 6 months (76.7 and 60.5\%, respectively), whereas in special schools only $20.3 \%$ of the treatments were ended. When regarding a shorter period of 13 weeks, in institutional care already $67 \%$ of the treatments had come to an end. In private practice and special schools, respectively, 39 and $15 \%$ of the treatments had stopped within 13 weeks of time.

Intervention Elements. Table 4 shows for how many patients the logopedist pointed out that a specific intervention element had been important in treatment. For example, the treatment element 'information/advice given to the patient' was important for $28.9 \%$ of the patients treated in private practice. In total, this intervention element was used in $24.7 \%$ of the patients. The element 'augmentative communication aid' could not be analysed as it was only registered in a few patients. All other intervention elements, except for velopharyngeal function exercise, showed significant differences among the fields. In the main group 'information/advice', the largest percentage were found for information/advice to both 
Raaijmakers, M.F., Dekker, J., Dejonckere, P.H., Zee, J. van der. Medical and educational fields in logopedics in the Netherlands: a comparison in historical and European perspective. Folia Phoniatrica et Logopaedica: 1998, 50(2), 80-91

patients and other people. 'Information to the patient' was mainly registered in institutional care. The main group 'supply with aid' was not often registered. In institutional care and special schools patients are supplied with hearing aids and with augmentative communication systems. In the other fields, these intervention elements were not often used. The group 'exercises of functions' showed some pronounced differences among the four fields. For example 'exercises of auditory perception' and 'exercises of auditory functions' were often indicated in special schools and far less in institutional care. Furthermore, in special schools large percentages were found for the intervention elements 'language form', 'language content' and 'language use', in contrast with the other three fields. The exercises of abilities in understanding, expressing and interaction showed a certain dichotomy. These exercises were mainly used in special schools and institutional care, whereas lower percentages were found in private practice and community care. Eating/ drinking excercises were most often used in institutional care.

\section{[TABLE 4]}

\section{DISCUSSION}

In this article, the four largest fields of logopedics practice in The Netherlands were compared. These four fields were considered to be dichotomised into education (community care and special schools) and medical care (private practice and institutional care). As was expected, some differences were found between medical and educational fields with regard to patient characteristics, referral, aspects of treatment and intervention elements. However, the fields that composed the two main fields not only showed similar characteristics, but some differences as well.

The present study indicates that logopedics practice in medical fields can be differentiated from that in educational fields. Logopedists in the educational fields were only concerned with children, whereas in both medical fields adults constituted a large part of the patients. In educational fields patients were mostly first noticed by a logopedist, probably as a result of screening programmes that are carried out in ordinary primary schools. In medical fields various persons may first notice a patient. Typical diagnostic assessments in medical fields included 'impairments of voice production/phonation', 'respiratory impairments' and 'body posture', while in educational fields the diagnostic assessment 'language development impairments' was characteristic. Logopedics in medical fields is also contrasted with the educational fields by the fact that the treatment period was usually ended within 6 months. Finally, in medical fields information was more likely to be given to the patient himself (even more so in institutional care), and certain exercises of functions were more often used than in educational fields, for example exercise of respiration, relaxation and voice quality.

Though some characteristics of the historical dichotomy are still visible in current logopedics, the results of this study also showed some important differences within the main fields. This will be illustrated for the fields in education and medical care, respectively.

Logopedics practice in the educational fields of community care and special schools differ with regard to several aspects. First, in community care children were younger than in special schools. And in special schools more children were assessed for 'impairments of auditory function', 'language development impairments', 'impairments of reading and writing'. Besides, children in special schools were more often assessed for disabilities and handicaps than were children in community care. In special schools, logopedists more often used certain exercises of functions (particularly language form, content and use) and much more exercises of abilities were used during treatment. This indicates that logopedics in special schools are more concerned with the effects of the impairment in daily life and the social functioning of children. This finding is in concordance with the specific task of logopedists in community care which is the prevention of communicative disorders in 
Raaijmakers, M.F., Dekker, J., Dejonckere, P.H., Zee, J. van der. Medical and educational fields in logopedics in the Netherlands: a comparison in historical and European perspective. Folia Phoniatrica et Logopaedica: 1998, 50(2), 80-91

normal children, whereas logopedists in special schools are to optimize the communication of children who were already found to have problems.

Between the fields of private practices and institutional care also some differences were found. In institutional care most patients were elderly, whereas in private practices the majority were children. In private practice most patients were referred by a general practitioner, but most patients were first noticed by parents or guardians. In institutional care most patients were first noticed and referred by a medical specialist. With regard to diagnostic assessments and intervention elements, some remarkable differences between private practice and institutional care were found. In institutional care disabilities and handicaps were more often assessed and exercises of abilities were more often used than was the case in private practice. This may be explained by the fact that particularly patients who have problems in daily life and social functioning will be institutionalised.

In conclusion, characteristics of the historical dichotomy of education and medical care are still demonstrable in current logopedics in The Netherlands. Thus, a knowledge of the origins of the profession is very useful to understand logopedics practice as it is today. Nevertheless, results also showed important differences within the fields of education and medical care. In addition, the field of private practice may be regarded as a mixture of medical and educational branches, as it not only resembled aspects of institutional care, but showed some characteristics that are comparable with the educational fields as well. Depending on the field in which they work, logopedists will therefore need specific expertise and training. It is recommended that differences between the fields are recognised and taken into account in (further) training courses for logopedists as well as in policymaking on logopedics.

This study concerned the situation of logopedics in The Netherlands. However, the historical development of logopedics shows resemblances in all countries, and logopedic fields in education and medical care will exist in most European countries. Lesser [17] already mentioned 'the different, conflictual, concepts world-wide of the logopedist as a medical auxiliary, a special education teacher or an autonomous professional-cumresearcher'. It would be interesting to study the practice of logopedics in the fields of education and medical care in other countries. For example, to compare countries where logopedics was strongly influenced by medical science or where emphasis is on education. Such a comparison could clarify to what extent the historical development of the profession affects current practice and it could provide a better understanding of the variety of logopedics practice throughout Europe.

\section{REFERENCES}

1 Pols L, Kuiper H: Logopedie en arbeidsmarkt (Logopedics and the Labour Market). Groningen, COWOG, 1991.

2 Hingstman L, Harmsen J: Beroepen in de extramurale gezondheidszorg 1994 (Professions in Extramural Health Care). Utrecht, De Tijdstroom/ NIVEL, 1994.

3 Driessen MJ, Dekker J, Zee J van der, Lankhorst G: Occupational therapy in hospital based care in The Netherlands: A comparison of occupational therapy in general care (nursing homes, rehabilitation centres and general hospitals) and psychiatric care. Occup Ther Int 1996; 3:142-156.

4 Becker KP, Sovak M: Lehrbuch der Logopädie (Textbook of Logopedics). Berlin, VEB Verlag Volk und Gesundheit, 1971.

5 Eldridge M: A History of the Treatment of Speech Disorders. Edinburgh, Livingstone, 1968.

6 Perello J: The History of the International Association of Logopedics and Phoniatrics.

Barcelona, Augusta, 1982.

7 Wendler J, Seidner W: Lehrbuch der Phoniatrie (Textbook of Phoniatrics), ed 2. Leipzig, Thieme, 1987.

8 Moerman G: De geschiedenis van het logopedie-onderwijs in Nederlandstalig België: Deel II (The history of logopedics training in Dutchspeaking Belgium: Part II). Logopedie 1992;5:45-49. 
Raaijmakers, M.F., Dekker, J., Dejonckere, P.H., Zee, J. van der. Medical and educational fields in logopedics in the Netherlands: a comparison in historical and European perspective. Folia Phoniatrica et Logopaedica: 1998, 50(2), 80-91

9 Schutte HK, Goorhuis-Brouwer SM: Handboek klinische stem-, spraak-, en taalpathologie (Clinical Voice, Speech and Language Pathology). Amersfoort/Leuven, ACCO, 1992.

10 Mondelaers BJE, Coets MC: Speech pathology in the European Union. Logop Foniatr 1995;65:127-134.

11 Kjær B: Denmark: Where therapy is a public responsibility. Speech Ther Pract 1991;4:17.

12 ASHA/IALP: International Directory of Education for Speech- Language Pathologists. Rockville, ASHA, 1994.

13 Daniel S, Schrey-Dern D: German therapists compete for clients. Speech Ther Pract 1991;4:16-17.

14 CPLOL: Press Book, Paris, CPLOL, year unknown.

15 Koster M, Dekker J, Groenewegen P: The position and education of some paramedical professions in The United Kingdom, The Netherlands, The Federal Republic of Germany and Belgium. Utrecht, NIVEL, 1991.

16 Raaijmakers MF, Dekker J: Logopedie in the Nederlandse gezondheidszorg (Logopedics in Dutch health care). Logop Foniatr 1995;9:206- 217.

17 Lesser R: The making of logopedists: An international survey. Folia Phoniatr 1992;44:105-125.

$18 \mathrm{GHI}$ (Chief Inspectorate of Public Health): Beroepsuitoefening van logopedisten, verslag van een onderzoek 17-21 april 1989 (Professional practice of logopedists, a study April 17-21, 1989). Rijswijk, GHI, 1990.

19 World Health Organisation: International Classification of Impairments, Disabilities and Handicaps. Geneva, WHO, 1980.

20 Raaijmakers MF, Dekker J, Dejonckere PH, Zee J van der: Reliability of the assessment of impairments, disabilities and handicaps in survey research on speech therapy. Folia Phoniatr 1995;47:199-209.

21 Huizingh KRE: Inleiding SPSS/PC+ 4.0 en Data Entry (Introduction to SPSS/PC+4.0 and Data Entry). Amsterdam, Addison-Wesley, 1993. 
Raaijmakers, M.F., Dekker, J., Dejonckere, P.H., Zee, J. van der. Medical and educational fields in logopedics in the Netherlands: a comparison in historical and European perspective. Folia Phoniatrica et Logopaedica: 1998, 50(2), 80-91

\section{TABLES}

Table 1. Percentages of patients by age and gender in four fields

\begin{tabular}{|c|c|c|c|c|c|}
\hline & \multicolumn{5}{|l|}{ Patients, $\%$} \\
\hline & $\begin{array}{l}\text { private practice } \\
(\mathrm{n}=518)\end{array}$ & $\begin{array}{l}\text { institutional care } \\
(\mathrm{n}=369)\end{array}$ & $\begin{array}{l}\text { community care } \\
(\mathrm{n}=326)\end{array}$ & $\begin{array}{l}\text { special schools } \\
(\mathrm{n}=548)\end{array}$ & $\begin{array}{l}\text { total } \\
(\mathrm{n}=1,761)\end{array}$ \\
\hline \multicolumn{6}{|l|}{ Age, years ${ }^{\mathbf{a}}$} \\
\hline $0-5$ & 35.4 & 14.2 & 66.6 & 8.8 & 28.5 \\
\hline $6-12$ & 27.8 & 3.8 & 32.4 & 72.3 & 37.4 \\
\hline $13-20$ & 9.2 & 1.2 & 0.9 & 18.9 & 8.8 \\
\hline $21-50$ & 18.1 & 18.0 & - & - & 9.1 \\
\hline $51+$ & 9.5 & 62.8 & - & - & 16.2 \\
\hline Mean (SD) & $17.5(20.4)$ & $58.2(28.9)$ & $5.6(1.9)$ & $9.0(3.4)$ & $20.2(24.7)$ \\
\hline \multicolumn{6}{|l|}{ Gender $\mathrm{b}$} \\
\hline Male & 56.3 & 45.5 & 56.7 & 67.9 & 57.8 \\
\hline Female & 43.7 & 54.5 & 43.3 & 32.1 & 42.2 \\
\hline
\end{tabular}

a Data on age were missing for 2 patients in the field 'special schools'.

b Data on gender were missing for 3 patients in the field 'private practice' and for 4 patients in the field 'institutional care'.

Table 2. Percentages of patients by referring physician in two fields and person who first noticed the patient in four fields (in 1,761 patients)

\begin{tabular}{|c|c|c|c|c|c|}
\hline & \multicolumn{5}{|c|}{ Patients, $\%$} \\
\hline & $\begin{array}{l}\text { private } \\
\text { practice } \\
(\mathrm{n}=518)\end{array}$ & $\begin{array}{l}\text { institutional } \\
\text { care } \\
(\mathrm{n}=369)\end{array}$ & $\begin{array}{l}\text { community } \\
\text { care } \\
(\mathrm{n}=326)\end{array}$ & $\begin{array}{l}\text { special } \\
\text { schools } \\
(\mathrm{n}=548)\end{array}$ & $\begin{array}{l}\text { total } \\
(\mathrm{n}=1,761)\end{array}$ \\
\hline \multicolumn{6}{|l|}{ Referring physician } \\
\hline General practitioner & 65.1 & 3.0 & & & \\
\hline Medical specialist & 21.6 & 92.1 & & & \\
\hline Dentist(-specialist) & 5.6 & 0.5 & & & \\
\hline Other & 4.1 & 3.0 & & & \\
\hline Not known/not relevant & 3.7 & 1.4 & & & \\
\hline Total & 100.0 & 100.0 & & & 100.0 \\
\hline \multicolumn{6}{|l|}{ Patient first noticed by } \\
\hline General practitioner & 8.2 & 4.4 & 0.3 & 0.4 & 3.6 \\
\hline Medical specialist & 12.4 & 66.5 & 0.3 & 0.8 & 18.2 \\
\hline Dentist(-specialist) & 5.7 & 1.1 & 0.3 & 0.4 & 2.1 \\
\hline Logopedist & 18.0 & 3.0 & 66.2 & 74.1 & 40.7 \\
\hline Teacher & 11.0 & 0.5 & 21.9 & 8.7 & 10.0 \\
\hline Parents/guardians & 19.4 & 3.0 & 7.4 & 6.0 & 9.6 \\
\hline Patient himself & 12.4 & 3.8 & - & - & 4.5 \\
\hline Nursing personnel & 0.4 & 11.0 & - & - & 2.5 \\
\hline School doctor & 3.9 & - & 2.3 & 0.6 & 1.8 \\
\hline Other & 10.0 & 7.4 & 1.9 & 9.3 & 7.8 \\
\hline Total & 100.0 & 100.0 & 100.0 & 100.0 & 100.0 \\
\hline
\end{tabular}


Raaijmakers, M.F., Dekker, J., Dejonckere, P.H., Zee, J. van der. Medical and educational fields in logopedics in the Netherlands: a comparison in historical and European perspective. Folia Phoniatrica et Logopaedica: 1998, 50(2), 80-91

Table 3. Percentages of diagnostic assessments in four fields (in 1,761 patients)*

\begin{tabular}{lllllll}
\hline Diagnostic assessments & Patients, \% & & & & \\
\cline { 2 - 6 } & private & institutional & community & special & total \\
& practice & care & care & schools & \\
& $(\mathrm{n}-518)$ & $(\mathrm{n}-369)$ & $(\mathrm{n}-326)$ & $(\mathrm{n}-548)$ & $(\mathrm{n}-1,761)$ \\
\hline
\end{tabular}

Impairments

1. Aural impairments and impaiments of auditory function Aural impairments* Impairments of auditory function*

7.1
12.4

ther aural impairments and impaiments of auditory function ${ }^{1}$

2. Voice impairments

Impairments of voice production/phonation*

Respiratory impairments

Other voice impairments

3. Language impairments

Language development impaiments*

Aphasia*

Other language impaiments*

4. Impairments of reading and writing/leaming Reading and writing

Other impairments of learn ing*

5. Impairments of articulation

Dysarthria*

Other impairments of articulation ${ }^{1}$

6. Nasality

Hyper/hyponasality

Other nasality 1

7. Impairments of fluency and thythm in speech Stuttering/cluttering/speoch rate ${ }^{*}$

Other imparments of fluence and thythm in speech ${ }^{1}$

8. Deviant mouth behaviours and sensorimotor impairments

Deviant mouth behaviour ${ }^{*}$

Impairments of swallowing*

Sensorimotor impaiments

$$
0.4
$$

13.3
5.4

7.7

6.4

15.9

38.9

11.2

0.8

0.3

2.2

1.0

27.6

21.6

21.7

18.4

17.8

20.8

17.8
6.1

9.3

22.4

10.6

10.6
29.0

42.0

26.1
2.7

2.7
1.2

29.0
8.7

$\begin{array}{ll}.0 & 76.8\end{array}$

- 0.6

$\overline{0.4}$

41.6

6.9

5.2

1.1

2.1

25.9

2.4

1.5

$-$

0.3

10.2

9.0
2.7

8.4

23.3

59.5

$-$

0.3

54.2

0.2

4.1

0.6

3.0

5.5

0.3

5.8

5.8
0.4

17.3

2.2

9.5

1.8

12.6
1.1

1.0

0.5

0.9

35.0

$13.3 \quad 46.0$

20.9

$46.0 \quad 35.0$

0.5

32.5

2.3

16.8

10.7

16.6

. Other impairment

Cognitive and psychobgical impairments ${ }^{*}$

Impairment of body posture*

Other impairments

$1.7 \quad 1.9$

$15.4 \quad 30.4$

1.9
30.4
6.8

6.8
4.3

$\begin{array}{ll}- & 0.4\end{array}$

$11.7 \quad 52.9$

0.9

0.6

Disabilities

1. Disability understanding communication*

2. Disability in expressing communication* ${ }^{*} \quad 48.8$

3. Disability in interacting during communication * 25.5

4. Disability in eating/drinking*

5. Other disabilities ${ }^{1}$

Handicaps

1. Oxupation handicap ${ }^{*}$

2. Social integration within family ${ }^{*}$

3. Social integration outside of family*

Significance level: ${ }^{*} \mathrm{p}-0.05$.

1 Could not be analysed. 
Raaijmakers, M.F., Dekker, J., Dejonckere, P.H., Zee, J. van der. Medical and educational fields in logopedics in the Netherlands: a comparison in historical and European perspective. Folia Phoniatrica et Logopaedica: 1998, 50(2), 80-91

Table 4. Percentage of intervention elements in 1,567 patients per field ${ }^{1}$

\begin{tabular}{|c|c|c|c|c|c|}
\hline & \multicolumn{5}{|c|}{ Patients, $\%$} \\
\hline & $\begin{array}{l}\text { private } \\
\text { practice } \\
(\mathrm{n}=512)\end{array}$ & $\begin{array}{l}\text { institutional } \\
\text { care } \\
(\mathrm{n}=327)\end{array}$ & $\begin{array}{l}\text { community } \\
\text { care } \\
(\mathrm{n}=181)\end{array}$ & $\begin{array}{l}\text { special } \\
\text { schools } \\
(n=547)\end{array}$ & $\begin{array}{l}\text { total } \\
(\mathrm{n}=1,567)\end{array}$ \\
\hline \multicolumn{6}{|l|}{ Information/advice } \\
\hline Patient* & 28.9 & 44.0 & 7.7 & 14.8 & 24.7 \\
\hline Others* & 27.1 & 15.9 & 31.5 & 18.8 & 22.4 \\
\hline Both* & 44.3 & 54.7 & 56.4 & 46.8 & 48.8 \\
\hline \multicolumn{6}{|l|}{ Supply with aid } \\
\hline Hearing aid* & 0.2 & 5.2 & & 5.9 & 3.2 \\
\hline Voice aid* & 0.2 & 0.3 & & 0.2 & 0.2 \\
\hline Augmentative communication aid ${ }^{2}$ & 0.8 & 6.4 & & 0.2 & 1.7 \\
\hline Other aid* & 3.3 & 12.2 & 1.7 & 1.1 & 4.2 \\
\hline Augmentative communication system ${ }^{*}$ & 2.1 & 5.5 & & 5.7 & 3.8 \\
\hline \multicolumn{6}{|l|}{ Exercises of function } \\
\hline Auditory perception* & 34.6 & 15.9 & 25.4 & 45.3 & 33.4 \\
\hline Auditory functions* & 16.2 & 4.6 & 11.6 & 32.7 & 19.0 \\
\hline Language forms* & 23.4 & 10.7 & 30.9 & 60.3 & 34.5 \\
\hline Language content ${ }^{*}$ & 19.1 & 26.0 & 27.6 & 61.6 & 36.4 \\
\hline Language use* & 16.4 & 22.0 & 15.5 & 49.2 & 28.9 \\
\hline Respiration* & 24.2 & 18.3 & 6.6 & 6.2 & 14.7 \\
\hline Relaxation* & 21.3 & 16.8 & 3.9 & 8.0 & 13.7 \\
\hline Voice quality* & 22.7 & 23.5 & 6.1 & 4.6 & 14.6 \\
\hline Vocal hygiene* & 16.2 & 13.8 & 6.6 & 3.1 & 10.0 \\
\hline Velopharyngeal function & 5.5 & 5.8 & 2.2 & 4.2 & 4.7 \\
\hline Phonemes* & 39.8 & 22.6 & 43.6 & 34.0 & 34.7 \\
\hline Mouth behaviour* & 16.4 & 12.8 & 28.2 & 17.0 & 17.2 \\
\hline Oral motor function ${ }^{*}$ & 34.4 & 30.3 & 39.8 & 29.3 & 32.4 \\
\hline Swallowing* & 13.7 & 25.4 & 12.7 & 7.9 & 14.0 \\
\hline Sensibility ${ }^{*}$ & 5.1 & 16.5 & 2.8 & 3.8 & 6.8 \\
\hline Emotions/cognitions* & 8.4 & 5.8 & 1.1 & 10.1 & 7.6 \\
\hline Fluency ${ }^{*}$ & 9.6 & 4.0 & 4.4 & 9.9 & 7.9 \\
\hline Other functions* & 9.6 & 13.5 & 1.7 & 17.9 & 12.4 \\
\hline \multicolumn{6}{|l|}{ Exercises of abilities } \\
\hline Understanding* & 10.4 & 23.5 & 15.5 & 40.6 & 24.3 \\
\hline Expressing* & 25.8 & 43.1 & 24.3 & 52.8 & 38.7 \\
\hline Start/maintain interaction ${ }^{*}$ & 17.2 & 33.6 & 10.5 & 33.8 & 25.7 \\
\hline Eating/drinking* & 7.2 & 23.2 & 5.0 & 2.9 & 8.8 \\
\hline Other abilities* & 8.8 & 8.0 & 1.1 & 8.6 & 7.7 \\
\hline \multirow{2}{*}{\multicolumn{6}{|c|}{$\begin{array}{l}\text { Significance level: }{ }^{*} \mathrm{p} \leq 0.05 \\
\text { Adds to more than } 100 \% \text { per field a }\end{array}$}} \\
\hline & & & & & \\
\hline \multicolumn{6}{|c|}{2 Could not be analysed as there were too few observations. } \\
\hline
\end{tabular}

